E3S Web of Conferences 1, 29008 (2013)

DOI: $10.1051 / \mathrm{e} 3$ sconf/20130129008

C Owned by the authors, published by EDP Sciences, 2013

\title{
Study on metal accumulation in aquatic plants of Cuciurgan cooling reservoir
}

\author{
E. Zubcov ${ }^{1}$, L. Biletchi ${ }^{2}$, E. Philipenko ${ }^{3}$ and L. Ungureanu $^{4}$ \\ ${ }^{1}$ Laboratory Hydrobiology and Ecotoxicology, Institute of Zoology, Academy of Sciences of Moldova, MD 2028, \\ Academiei str., 1, ecotox@yahoo.com \\ ${ }^{2}$ Laboratory Hydrobiology and Ecotoxicology, Institute of Zoology, Academy of Sciences of Moldova, MD 2028, \\ Academiei str., 1, lucia_biletchi@mail.md \\ ${ }^{3}$ Laboratory Hydrobiology and Ecotoxicology, Institute of Zoology, Academy of Sciences of Moldova, MD 2028, \\ Academiei str., 1, philipenko@spsu.ru \\ ${ }^{4}$ Laboratory Hydrobiology and Ecotoxicology, Institute of Zoology, Academy of Sciences of Moldova, MD 2028, \\ Academiei str., 1, ecotoxmd@mail.ru, ungur02laura@yahoo.com
}

\begin{abstract}
The biomass of plants from the Cuciurgan cooling reservoir of the Moldovan Thermal Power Plant is dependent on the reservoir thermofication and bore considerable modifications. The contents of many metals in aquatic plants were highly correlated with their contents in water: $r=0,87-0,91$. The dynamics of trace element accumulation depends on seasonal factors. From the beginning of spring to the end of summer and beginning of autumn, the concentrations of trace elements increased by large increments, while with the decrease in temperature below $10^{\circ} \mathrm{C}$, an opposite effect was observed. After plant death, a significant part of accumulated trace elements are released into the water, in the most cases this being associated with organic compounds. More than one half of the amount of trace elements is deposited with the decaying plants in the bottom sediments. Therefore, difficulties may arise, while identifying the role of aquatic plants in biogenic migration of metals in aquatic ecosystems and water purification processes.
\end{abstract}

Key words: Heavy metals, aquatic plants, biomonitor, migration, accumulation, pollution.

\section{Introduction}

The aquatic plants are one of the main components of biota of aquatic ecosystems, playing an important role in the migration process and circuit of chemical elements. The usage of aquatic plants for assessment of pollution level of aquatic ecosystems with heavy metals has a range of advantages in comparison with their determination directly in the water (Zubcov E. et. all, 2009). The plant capacity of metal accumulation offers the possibility to substantially reduce the volume of analyzed samples, to obtain an integral picture on the mean contents of heavy metals in a given period of time, although their content in water can highly fluctuate. It is enough to mention that in Cuciurgan reservoir more than $80 \%$ of suspended matter, which penetrate into the reservoir with the water of Turunciuc branch of the Dniester River, are absorbed in the stands from the lower sector of the reservoir. The stands of Phragmites australis, located in the area of wastewaters discharge, absorb more than $60 \%$ of suspended matter.
The Cuciurgan reservoir refers to the highly thermophicated cooling reservoirs of thermal power plants, which started to be exploited in 1964. The modification of water temperature led to the changes in hydrochemical regime of water body and determined the peculiarities of its biota.

\section{Materials and Methods}

Systematic researches on the metal dynamics $(\mathrm{Mn}, \mathrm{Pb}, \mathrm{Al}$, $\mathrm{Ti} \mathrm{Ni}, \mathrm{Mo}, \mathrm{V}, \mathrm{Cu}, \mathrm{Zn}$ ) in aquatic plants from the water bodies of Moldova have been carried out during the last 20 years. Plant samples (Phragmites australis, Typha latifolia), Potamogeton pectinatus, Potamogeton perfoliatus, Potamogeton crispus, Ceratophyllum demersum, Myriophyllum spicatum, Lemna minor, Hydrocharis morsus-ranae, Cladofora, Enteromorpha, Najada marina) have been collected mainly during the vegetation period, but in some cases- also in winter. Concentrations of metals were determined by direct absorption in air-acetylene flame using an atomic 
absorption spectrophotometer (AAS-3 "Carl Zeiss" company, Germany) as described elsewhere (Sapozhnikova et al. 2005). Last three years metals were determined by using a Perkin-Elmer atomic absorption spectrophotometer AAnalist 400 with the HGA 900 graphite furnace (Analytical Methods for Atomic Absorption Spectroscopy, 1996).

\section{Results and Discussion}

The range of variation of metal concentrations in investigated aquatic plants is quite large and it is conditioned by the plant taxonomic peculiarities, metal content in water and bottom sediments, chemical properties and biological role of investigated chemical elements and, definitely, by the season.

As result of the simultaneous sampling of plants in a given sector of reservoir, it was determined that preponderantly, the contents of $\mathrm{Mn}, \mathrm{Pb}, \mathrm{Al}, \mathrm{Ti}, \mathrm{Mo}$ and $\mathrm{V}$ were higher in filamentous algae (Cladofora sp., Enteromorpha sp.), and those of $\mathrm{Ni}, \mathrm{Cu}$ and $\mathrm{Zn} \mathrm{-} \mathrm{in}$ Myriophyllum spicatum and Lemna minor.

The lowest concentrations of most of the investigated metals were registered in aerial parts of the Phragmites australis, Typha latifolia and Hydrocharis morsus-ranae (Tab. 1).

Table. 1. Range of variation of metal concentrations in aquatic plants from Cuciurgan Reservoir,

$\mu \mathrm{g} / \mathrm{g}$ abs.dry mass

\begin{tabular}{|c|c|c|c|c|c|c|c|c|c|}
\hline & $\mathrm{Mn}$ & $\mathrm{Pb}$ & $\mathrm{Al}$ & $\mathrm{Ti}$ & $\mathrm{Ni}$ & Mo & $\mathrm{V}$ & $\mathrm{Cu}$ & $\mathrm{Zn}$ \\
\hline \multicolumn{10}{|c|}{ Phragmites australis } \\
\hline $\min -$ & $78,2-$ & $0,7-$ & $23,0-$ & $2,7-$ & $6,2-$ & $1,0-$ & $1,7-$ & $3,7-$ & 7,9- \\
\hline $\max$ & 580 & 15,8 & 288 & 23,2 & 27,2 & 12,7 & 17,9 & 28,1 & 87,6 \\
\hline \multicolumn{10}{|c|}{ Typha latifolia } \\
\hline $\min -$ & $155-$ & $2,8-$ & $21,2-$ & $7,9-$ & $5,4-$ & $2,0-$ & $2,7-$ & $4,8-$ & $11,9-$ \\
\hline $\max$ & 420 & 17,2 & 299 & 23,4 & 25,7 & 9,9 & 16,7 & 34,1 & 78,9 \\
\hline \multicolumn{10}{|c|}{ Potamogeton pectinatus } \\
\hline $\min -$ & $220-$ & $4,7-$ & $38,9-$ & $11,3-$ & $7,3-$ & $2,1-$ & $3,8-$ & $14,7-$ & 22,9 \\
\hline $\max$ & 402 & 18,7 & 321 & 26,9 & 39,4 & 21,8 & 18,7 & 38,1 & 163 \\
\hline \multicolumn{10}{|c|}{ Potamogeton perfoliatus } \\
\hline $\min -$ & $122-$ & $3,2-$ & $47,7-$ & $23,7-$ & $6,6-$ & $1,9-$ & $6,4-$ & $17,4-$ & 38,8 \\
\hline $\max$ & 382 & 14,8 & 203 & 25,2 & 26,7 & 17,8 & 14,9 & 38,9 & 141 \\
\hline \multicolumn{10}{|c|}{ Potamogeton crispus } \\
\hline $\min -$ & $175-$ & $3,2-$ & $47,7-$ & $9,7-$ & $6,6-$ & $1,9-$ & $6,4-$ & $17,4-$ & 38,8 \\
\hline $\max$ & 438 & 14,8 & 203 & 25,2 & 26,7 & 17,8 & 14,9 & 36,7 & 134 \\
\hline \multicolumn{10}{|c|}{ Ceratophyllum demersum } \\
\hline $\min -$ & $284-$ & $3,9-$ & 82,9 & $9,8-$ & $7,8-$ & $2,8-$ & $5,6-$ & $15,9-$ & $47,8-$ \\
\hline $\max$ & 565 & 17,2 & 234 & 21,6 & 37,9 & 14,9 & 15,7 & 38,3 & 109 \\
\hline \multicolumn{10}{|c|}{ Myriophyllum spicatum } \\
\hline $\min -$ & $166-$ & $2,8-$ & $49,9-$ & $22,2-$ & $34,2-$ & $3,4-$ & $5,4-$ & $38,2-$ & $87-$ \\
\hline $\max$ & 421 & 9,9 & 99,9 & 41,3 & 86,7 & 12,2 & 9,5 & 66,7 & 315 \\
\hline \multicolumn{10}{|c|}{ Lemna minor } \\
\hline $\min -$ & $240-$ & $2,3-$ & 23,9 & $12,7-$ & $17,8-$ & $2,4-$ & $4,9-$ & $18,9-$ & $41,5-$ \\
\hline $\max$ & 588 & 13,2 & 43,7 & 41,4 & 68,3 & 18,5 & 11,3 & 62,5 & 193 \\
\hline \multicolumn{10}{|c|}{ Hydrocharis morsus-ranae } \\
\hline $\min -$ & $155-$ & $2,9-$ & 33,9 & $8,8-$ & $34,8-$ & $9,6-$ & $30,1-$ & $25,7-$ & $49,8-$ \\
\hline $\max$ & 434 & 14,2 & 86,9 & 26,2 & 59,6 & 23,7 & 39,9 & 54,6 & 178 \\
\hline \multicolumn{10}{|c|}{ Cladofora, Enteromopha } \\
\hline $\min -$ & $290-$ & $3,2-$ & $39,2-$ & $22,2-$ & $22,4-$ & $3,9-$ & $2,9-$ & $24,3-$ & $48,4-$ \\
\hline $\max$ & 844 & 22,2 & 250 & 59,7 & 63,7 & 33,8 & 37,2 & 60,4 & 189 \\
\hline
\end{tabular}




\begin{tabular}{|c|c|c|c|c|c|c|c|c|c|}
\hline \multicolumn{10}{|c|}{ Najada marina } \\
\hline $\min -$ & $149-$ & $2,9-$ & $28,9-$ & $11,7-$ & $23,8-$ & $4,9-$ & $5,0-$ & $28,2-$ & $87,2-$ \\
$\max$ & 497 & 13,7 & 47,9 & 21,9 & 34,9 & 8,9 & 10,3 & 124 & 173 \\
\hline
\end{tabular}

The contents of many metals in aquatic plants were highly correlated with their contents in water: $\mathrm{r}=0.87-0.91$ (Fig.1).
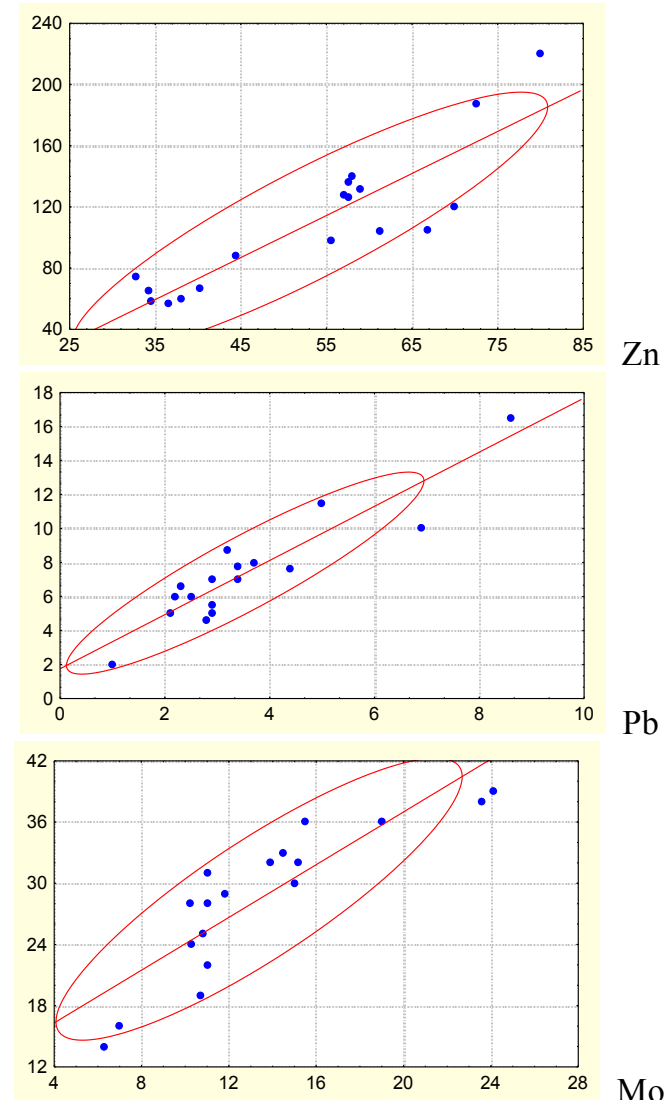

$\mathrm{Pb}$

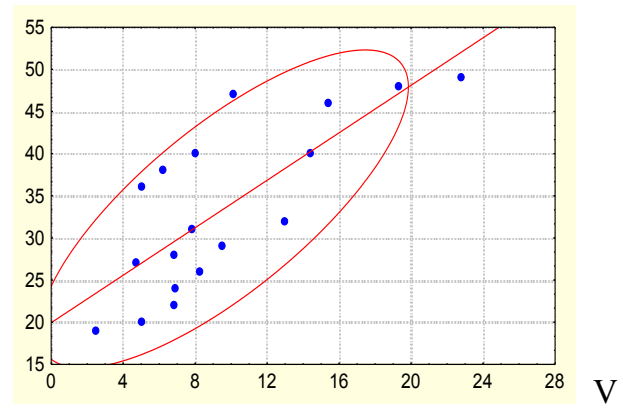

Figure 1. Dependence of metal accumulation level in aquatic plants on their content in water (horizontal axismetal content in water, $\mu \mathrm{g} / \mathrm{l}$; vertical axis - metal content in aquatic plants, $\mu \mathrm{g} / \mathrm{g}$ abs.dry mass)

The calculations included the metal mean contents in hydatophytes and pleustophytes (free-floating): Potamogeton pectinatus, Potamogeton perfoliatus, Potamogeton crispus, Ceratophyllum demersum, Myriophyllum spicatum, Lemna minor, Hydrocharis morsus-ranae, Cladofora, Enteromorpha, Najada marina. Obviously, the dynamics of these metals in reservoir water displays an fluctuting character, which is determined by an entire complex of natural and anthropogenic factors.

Withal, the above mentioned dependence was not revealed for helophytes (e.g. Phragmites australis, Typha latifolia), which metal accumulation level depends, also, on the composition of bottom sediments.
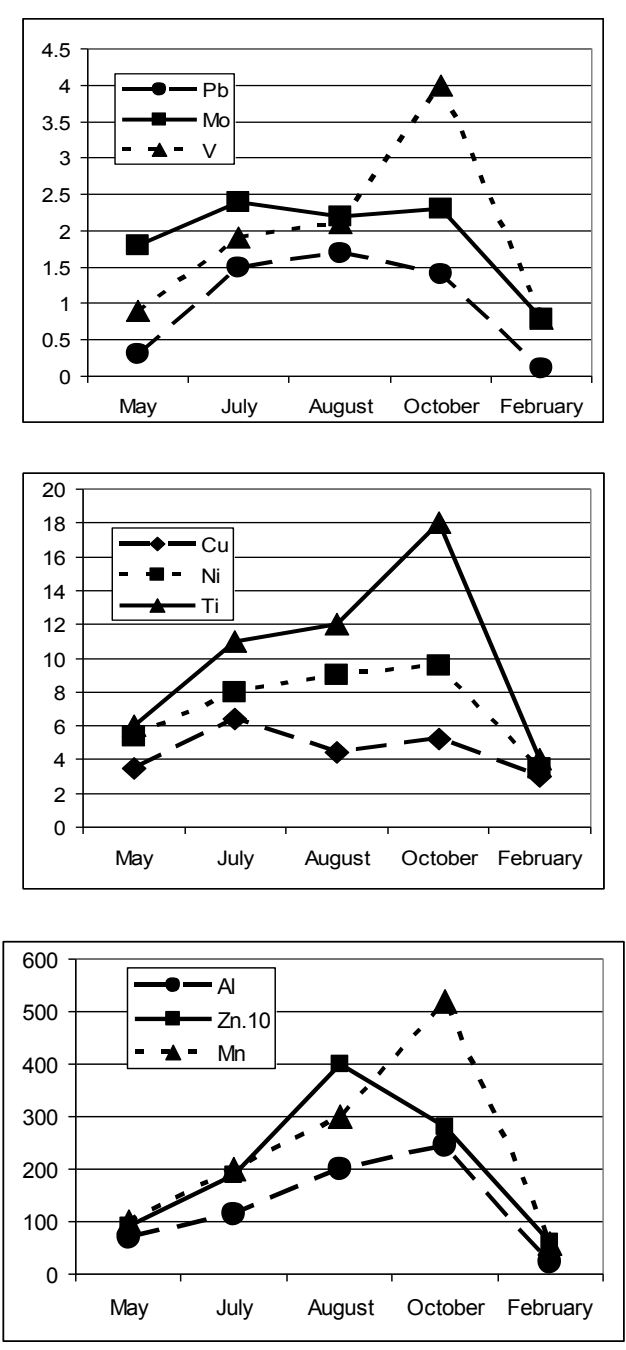

Figure 2. Seasonal features of metal accumulation in leaves and aerial stem of Phragmites australis (vertical axis- $\mu \mathrm{g} / \mathrm{g}$ abs.dry mass)

With rare exceptions, the accumulation dynamics of a range of metals, such as $\mathrm{Zn}, \mathrm{Mn}, \mathrm{Cu}, \mathrm{Co}, \mathrm{Mo}$ and $\mathrm{Al}$ demonstrated seasonal patterns. Thus, the analyze of metal accumulation in leaves and stem (both aerial and submerged) of Phragmites australis reveals that their contents increase by large increments from spring to end of summer- beginning of autumn (Fig. 2 ).

In autumn, with the decrease of water temperature 
below $10^{\circ} \mathrm{C}$, an opposite phenomenon was observed - a clear enough decrease of metal contents in aerial parts of plants, accompanied by their slightly increase in root parts. Specifically in this period an increase of metals content in the mud solutions, obtained from the bottom sediments picked up in stands, was registered. All this conduct to the assumption that a partial flow of metals from aquatic plants to the bottom sediments, has occurred in autumn through their root systems.

In later autumn and in the beginning of winter, when the aerial plant parts perish, the metal content in semi-decayed leaves and stems consists of less that $10-20 \%$ of that from the end of the summer. Probably, an important part of metals penetrates into the water layer both in dissolved and suspended forms.

However, in spite of variation of metal accumulation, some similar regularity for concentrating of one or another metal have been tracked. Thus, in most of the cases and for majority of aquatic plants, the trace elements have formed the following decreasing row, in conformity to their contents: $\mathrm{Mn}>\mathrm{Al}>\mathrm{Zn}>\mathrm{Ni}>\mathrm{Cu}>$ $\mathrm{Ti}>\mathrm{V}, \mathrm{Mo}, \mathrm{Pb}$.

One of the main indices of accumulation of aquatic plants is the biological accumulation coefficient, which can be calculated as the ratio between the metal concentration in hydrobionts and in water. The following range of variation of accumulation coefficient was obtained (by revealing the minimal and maximal trace element concentrations): for $\mathrm{Mn}$ - 3630-50540, lea 83-6520, Al - 367-142900, titan - 1210-49750, Ni 735-30900, Mo - 313-2600, V - 357-8310, Cu346-30800, and $\mathrm{Zn}-1170-10090$. The figures evidently prove that investigated aquatic plants are metal macroconcentrators.

The biomass of filamentous algae has increased suddenly during the last years, they compactly covering the reservoir bottom. Two sectors- upper and medial ones, are almost entirely covered by a layer of these algae.

In accordance with the data of Moldovan Thermal Power Plant specialists, currently the biomass of filamentous algae reaches $2-3 \mathrm{~kg}$ per square meter, they covering about $70 \%$ of entire area of cooling reservoir. Taking in account these figures, it was quantified that filamentous alga alone can put in circuit: manganese $1.15 \mathrm{~kg} / \mathrm{ha}$, lead $-0.01 \mathrm{~kg} / \mathrm{ha}$, aluminium $-0.79 \mathrm{~kg} / \mathrm{ha}$, titanium $-0.29 \mathrm{~kg} / \mathrm{ha}$, nickel $-0.68 \mathrm{~kg} / \mathrm{ha}$, molybdenum $-0.44 \mathrm{~kg} / \mathrm{ha}$, vanadium $-0.26 \mathrm{~kg} / \mathrm{ha}$, copper- $0.69 \mathrm{~kg} / \mathrm{ha}$, zinc $-1.65 \mathrm{~kg} / \mathrm{ha}$, cadmium $-0.001 \mathrm{~kg} / \mathrm{ha}$.

\section{Conclusion}

The metal accumulation in aquatic plants is a function of plant taxonomic features, dynamics of their content in water and bottom sediment of reservoirs and water streams, and season.

Aquatic plants, particularly Potamogeton pectinatus, Potamogeton perfoliatus, Potamogeton crispus, Ceratophyllum demersum, Myriophyllum spicatum, Lemna minor, Hydrocharis morsus-ranae, Cladofora, Enteromorpha, Najada marina can be used as monitoring organisms in the metal biomonitoring of water ecosystems.

Aquatic plants can act as a source of secondary metal pollution of water layer, but simultaneously, an important amount of metals, accumulated in submerged part of stem (especially the part covered by dense suspensions) and root system is preserved in bottom sediments.

Moreover, at the death of aquatic plants and their deposition on the reservoir bottom, a notably quantity of metals is absorbed on their surface.

\section{Acknowledgements}

We would like to extend our appreciation to SCSTD, Moldova (projects 06.411.012F $11.817 .08 .15 \mathrm{~A}$ ).

\section{References}

Analytical Methods for Atomic Absorption Spectroscopy (1996). The Perkin-Elmer Corporation.

Sapozhnikova Y, Zubcov N, Hungerford S, Roy LA, Boicenco N, Zubcov E, Schlenk D (2005) Evaluation of pesticides and metals in fish of the Dniester River, Moldova. Chemosphere 60: 195 205.

Zubcov Elena, Ungureanu Laurentia, Ene Antoaneta, Bagrin Nina, Borodin Natalia, (2009) Influence of nutrient substances on phytoplankton from Prut River, Annals of the University Dunarea de Jos of Galati, Fascicle II - Mathematics, Physics, Theoretical Mechanics, Year I(XXXII), ISSN 2067 - 2071, P. 68-72. 